\title{
COVID-19 impact on dental education in Iraq; challenges and future implications
}

\author{
Ammar N.H. Albujeer ${ }^{1,2,3}$,
}

\author{
${ }^{1}$ Nab'a Al-Hayat Foundation for Medical Sciences and Health Care, Najaf, Iraq. \\ ${ }^{2}$ College of Dentistry, Al-Farahidi University, Baghdad, Iraq. \\ ${ }^{3}$ School of Dentistry, Tehran University of Medical Sciences, Tehran, Iran. \\ Corresponding Author: Ammar N.H. Albujeer (E-mail: ammar.dent@yahoo.com) \\ (Submitted: 20 October 2020 - Revised version received: 28 October 2020 - Accepted: 290ctober 2020 - Published online: 30 October 2020)
}

\section{Dear Editor-in-Chief:}

As the Coronavirus pandemic exacerbates, its disproportionate impacts affects all aspects of the community and life. The dental schools and dentistry profession were in the front line of this changes and bear a large portion of this crisis. ${ }^{1}$ This burdens added to the dental education in Iraq in addition to its current challenges. ${ }^{2,3}$ Until October 28, 2020, Iraq registered 463,951 cases, and 10,770 persons died from COVID-19, of which $2.3 \%$ from the infected cases and $6 \%$ of the death cases were dentists. ${ }^{4}$ Upon on the WHO recommendations along with this high mortality rate made the policy makers in Iraqi Ministry of Health $(\mathrm{MOH})$ and Ministry of Higher Education and Scientific Research (MOHESR) take the decisions for national-wide lockdown and closure of dental schools in Iraq and minimize the dentists presence in public hospitals and dental centers to $25 \%$, and just for emergency patients need since March 1, 2020. This decision affected the 5th stage students which had already graduate in September 2020 from taking the enough clinical training and patient management, while the successful e-learning coverage the theoretical educational sessions well. As its impossible to certain the end of this pandemic and this will be a real threaten for the new graduated dentists skills and knowledge to manage patients, the policy makers must change the dental education program in Iraq and to add the (Exit Interview) for all graduated students which would make a need assessment for the real need, and design an intensive course for them upon on their needs that would help dental schools and educators to ensure the dental education quality assurance. This intensive course could be like the General Practice Residency (GPR) which is accredited in USA. ${ }^{5}$ This model could be considered in other effected countries which has the same lockdown and closed policy like Iraq. Keywords: COVID-19, Dental Education, Dentistry, Iraq

\section{References:}

1. Machado, RA, Bonan, PRF, Perez, DEDC and Martelli JÚnior, H. COVID-19 pandemic and the impact on dental education: discussing current and future perspectives. Braz Oral Res. 2020;34.

2. Khoshnevisan, MH, Albujeer, AN, Taher, AA and Almahafdha, A. Dental education in Iraq: issues, challenges and future. J Contemp Med Sci, 2017;3(11):260-263.

3. Albujeer, AN, Khami, MR and Almahafdha, A. Private dental schools in Iraq: A real threat to the dental profession. Iran J Public Health. 2020;49(1):201-202.

4. Statistics of COVID-19, 2020; Ministry of Health, Iraq

5. Lau, A, Dodson, TB, Sonis, ST and Kaban, LB. An outcomes study of 40 years of graduates of a general practice dental residency. J Dental Educ. 2015;79(8):888-896 